\title{
Methodology of the experimental study about the effective function of the specialized motor transport enterprise
}

\author{
Igor Lyubimov ${ }^{1 *}$, Alexey Melnikov ${ }^{1}$, and Konstantin Manayev ${ }^{1}$ \\ ${ }^{1}$ Orenburg State University, 13 Prospect Pobedy, Orenburg, 460018, Russia
}

\begin{abstract}
The article presents the methodology of the optimization for the structure of the motor transport and container fleet of the specialized motor transport enterprise at the heart of which the principles of program and target planning and linear programming are used.
\end{abstract}

\section{Introduction}

Functioning and developing of any municipality is followed by the formation of the solid domestic waste (SDW) as a result of the population activity, enterprises, organizations and other subjects of economic activity. The activities organization for collecting and removing of solid domestic waste is regulated by normative legal acts at federal and municipal levels. The enterprises which are carrying out collecting and removing of waste have to provide the observance of these normative legal acts and also the contracts implementation which were signed with the subjects of economic activity with the minimum labor and material costs. In this regard the issues about the optimization of the collecting and removing infrastructure of solid domestic waste from the territory of the municipal unit are relevant.

\section{Material and methods}

The effective decision of an objective is possible with the use of system approach in which the collecting and removing system of solid domestic waste is presented in the form of the interconnected and interacting elements.

The drafted theoretical provisions [1-4, 7-9] set the interrelation between the cost of SDW collecting and removing $\left(1 \mathrm{~m}^{3}\right)$ and the structure of the motor transport and container fleet.

The purpose of the experimental study is the confirmation and the assessment of the adequacy of elaborated theoretical provisions.

Proceeding from the research purpose the experiment tasks were also determined:

- to prove the experimental base of the research;

- to determine the stages of experimental work and the tasks on each of them;

- to perform the analysis, interpretation and handling of the obtained data, to prove the reliability of the put forward research hypothesis;

*Corresponding author: 1yubimovii@gmail.com 
- to develop scientific and methodical recommendations for the practical use of the methodology on the choice of the rational quantity and the vehicles type, the containers quantity and type of the specialized motor transport enterprise.

The block scheme of the general methodology for conducting the experimental study about the setting of the interrelation character between the cost of SDW collecting and removing $\left(1 \mathrm{~m}^{3}\right)$ and the structure of the motor transport and container fleet is presented in figure 1 .

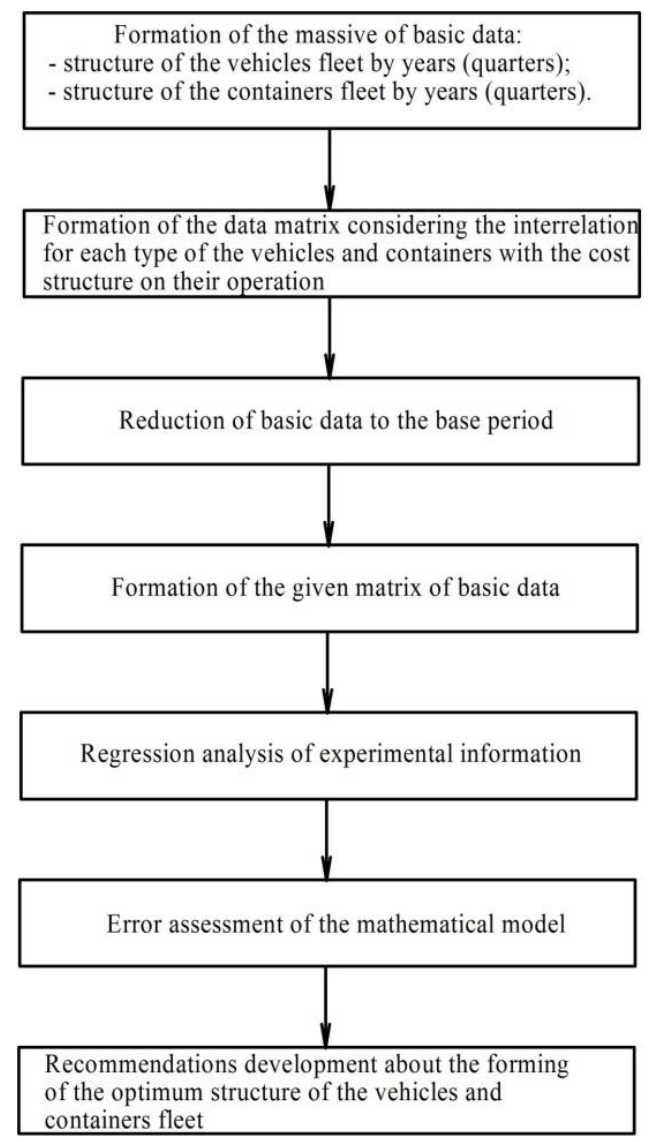

Fig. 1. The block scheme of the general methodology for conducting experimental study [10].

The experimental research is carried out in two stages. The purpose of the first stage is the collection and the preliminary handling of the results of the enterprise practical activities considering the interrelation between the structure of the vehicles and container fleet and the effectiveness indicators of the enterprise work.

The second stage determines the values of fixed and variable components of the mathematical models and on this basis the complex of organizational and technical actions for the structure optimization of the vehicles and container fleet is developed $[6,8]$.

\section{Theory and calculation}

The indicators of the enterprise functioning provided in the ordered sequence are used as the basic data which are necessary for the values establishment of the mathematical model.

As the effectiveness indicators of the motor transport enterprise functioning we accept: 
- the structure of cost value for collecting and removing of $1 \mathrm{~m}^{3}$ of solid domestic waste (SDW);

- the enterprise income;

- amount of transported SDW;

- the structure of the vehicles fleet;

- the structure of the containers fleet $[5,9]$.

To assess effectively the impact of the fleet structure change on the cost of the transport operation unit as time intervals we accept the year quarters of previous years of the enterprise work. It is connected both with the minimum possible period in which it is possible to assess the impact of the structure change on the indicators of the enterprise work, and with the parameters of the accounting financial period.

The cost of the transport operation unit is established proceeding from the actual amount of works during corresponding periods, and also from the operating costs given by the base year [11-14].

With the research purpose of the interrelation between the rolling stock structure and the container fleet and the cost of the transport operation unit we will present the functional dependence in the following form:

$$
F_{n}=\frac{C_{\text {totn }}}{Q_{n}}
$$

where $F_{n}$ - the cost of the transport operation unit on the considered n-period, rub. $/ \mathrm{m}^{3}$; $C_{\text {tot } n}$ - general costs of the transport work performance on the considered n-period, rub.; $Q_{n}$ - total amount of SDW removing on the considered $n$-period, $\mathrm{m}^{3}$.

The determination of the given operating costs of the rolling stock and container fleet on the considered n-period of the operation is performed on the basis of the dependence use:

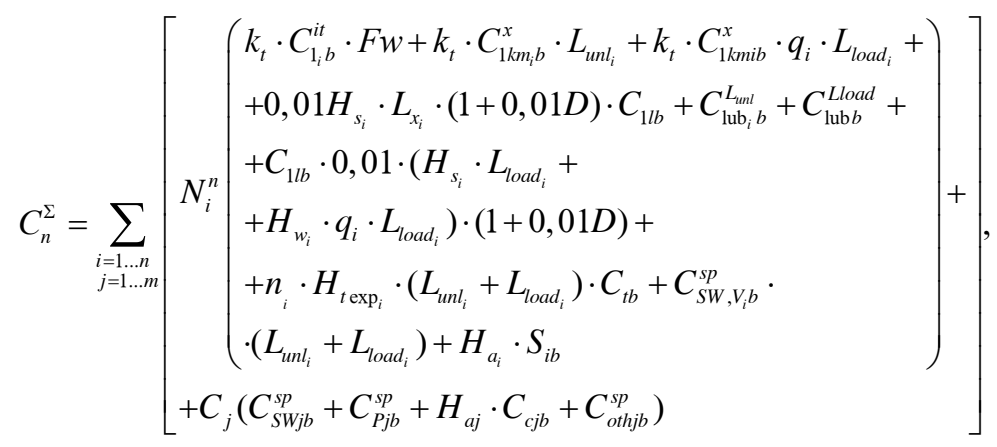

where $N_{i}^{n}$ - the vehicles quantity of $i$-group on n-period of operation; $C_{1 i b}^{t i}$ - driver's tariff rate during idle time of $i$-vehicle on the basic operation period; $C_{1 k m_{b} b}^{x}$ - the cost of one kilometer at a single run of $i$-vehicle on the basic operation period; $C_{1 l b}$ - fuel litre cost on the basic operation period; $C_{t b}$ - the tires cost on the basic operation period; $S_{i b}$ - the cost of $i$-vehicle on the basic operation period; $C_{1 k m, b}^{x}$ - driver's tariff rate during freight transportation of $i$-vehicle on the basic operation period; $C_{j}-$ the cost per unit on the containers service of $j$-group on the basic operation period; $C_{P j b}^{s p}-$ the cost per unit on the containers maintenance of $j$-group on the basic operation period; $C_{c j i b}^{s p}-$ the cost of one container of $j$-group on the basic operation period; $C_{o t h j b}^{s p}-$ other cost per unit on the containers operation of $j$-group on the basic operation period. 
Thus, the given total costs per unit on collecting and removing of solid domestic waste of $i$-group for the vehicles and $j$-group for the containers on $n$-operation period, can be provided as:

$$
f_{i j}^{n}=\frac{C_{i}^{n}+C_{k j}^{n}}{Q_{i j}^{n}},
$$

where $C_{i}^{n}$ - the given costs on the operation of $i$-group for the rolling stock; $C_{c j}^{n}$-the given costs on the operation of $j$-group for the containers; $Q_{i j}^{n}$ - the given volume of SDW collecting and removing by $i$-group of the rolling stock using containers of $j$-group.

This expression is used for the optimization of the vehicles and container fleet structure on sensitivity.

The establishment of the interrelation character between the vehicles and container fleet structure and the cost of the transport operation unit is carried out by the method of the regression analysis.

The regression analysis assumes the theoretical analysis of the studied phenomenon nature for the purpose of the determination of the factors circle exerting impact on the behavior of the resulting sign.

Figure 2 represents the determination algorithm of the regression equation coefficients that allows to establish the interrelation of the vehicles and container fleet structure with the cost of collecting and removing of $1 \mathrm{~m}^{3}$ of solid domestic waste.

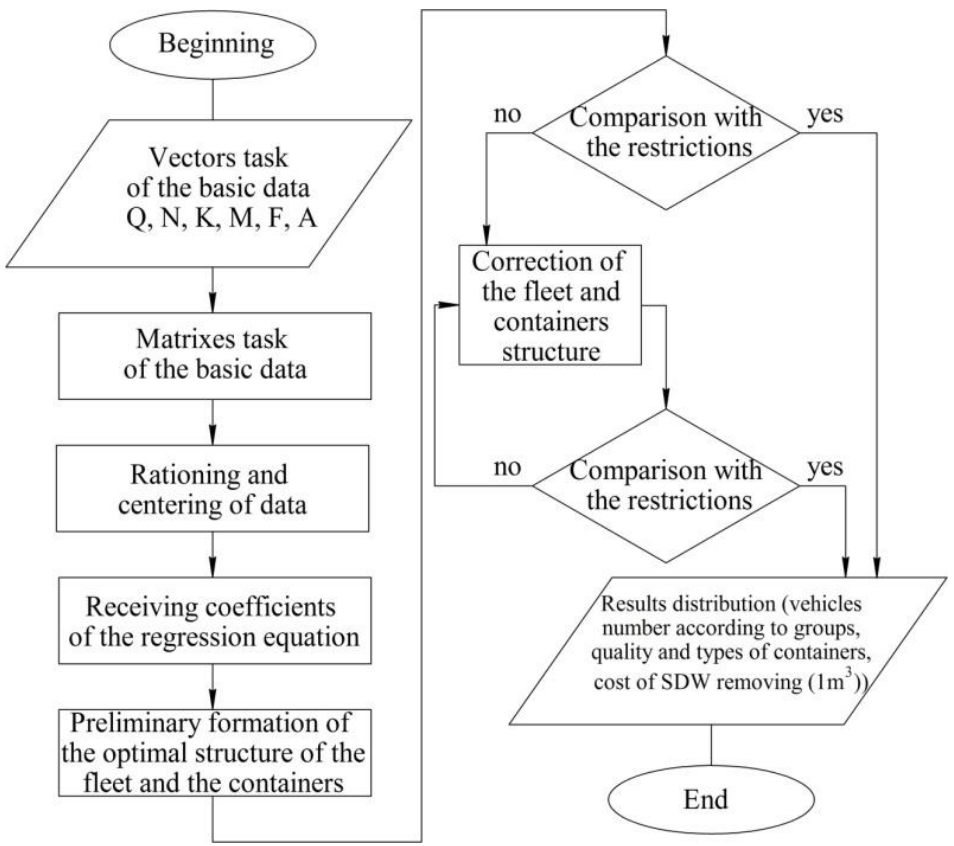

Fig. 2. The establishment algorithm of the regression coefficients parameters.

The regression analysis was carried out with the use of the applied software product "Statistica" during the scientific research.

The algorithm was formed for the optimization of the vehicles and container fleet structure of the specialized motor transport enterprise for conducting the second stage of the experimental research.

The algorithm of the rational structure determination for the vehicles and container fleet is provided in figure 3 . 
1. At the initial stage the fleet is corrected by the group models removal with the regression coefficients making a powerful contribution in cost value increasing of $1 \mathrm{~m}^{3}$ of SDW collecting and removing.

2. The amount of SDW which needs to be removed after removing inefficient types of the vehicles is determined.

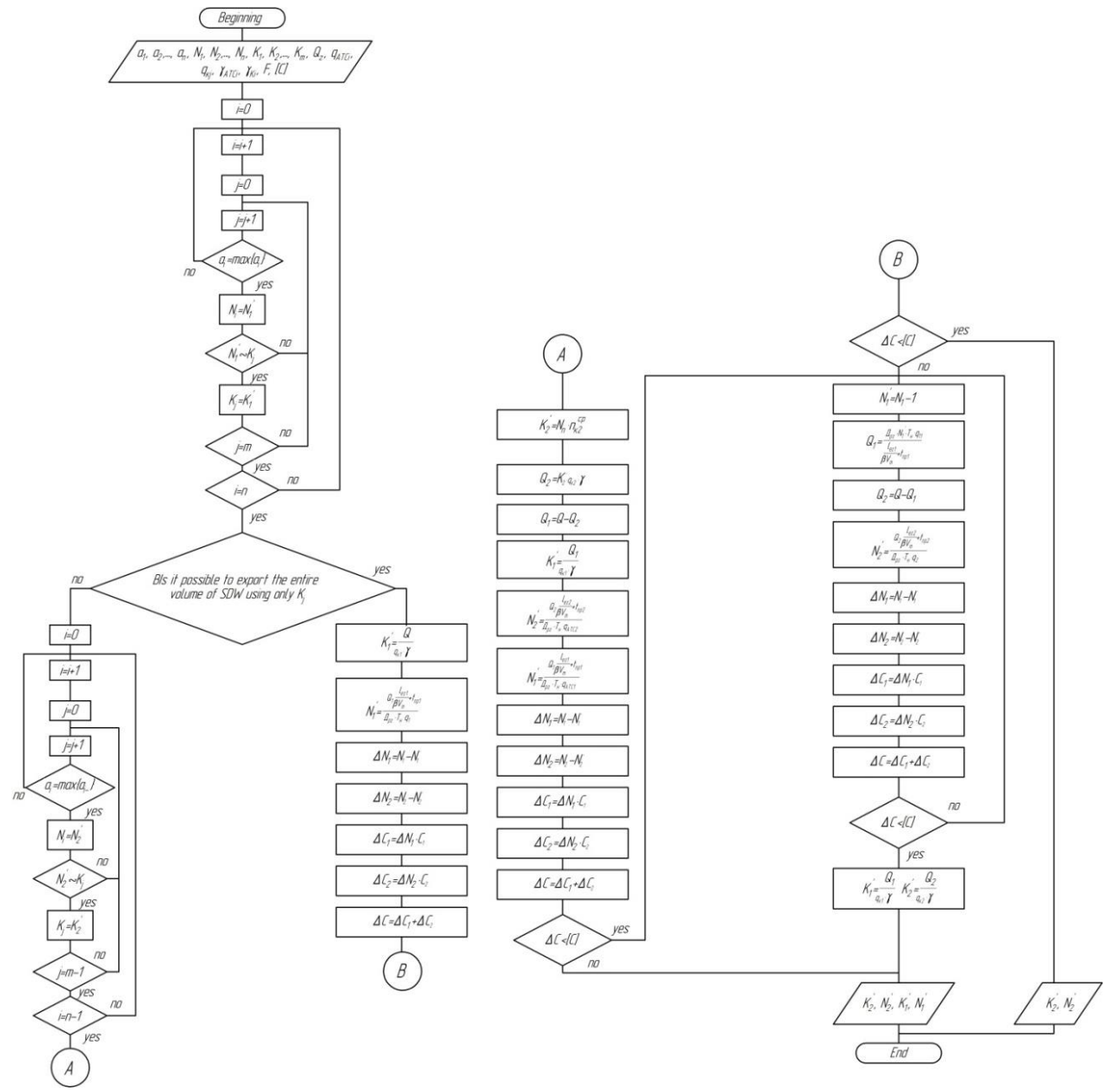

Fig. 3. The algorithm of the rational structure determination for the vehicles and containers fleet

$a_{i}$ - coefficients of the regression equation; $N_{i}$ - the existing number of vehicles in $i$-group, un.; $C_{j-}$ the existing number of containers in j-group, un.; $q_{V i}$ - vehicles capacity in $i$-group, $\mathrm{m}^{3} ; q_{c i}-$ containers capacity in $j$-group, $\mathrm{m}^{3} ; \gamma_{V i}$ - compacting factor for SDW of vehicles in i-group; $\gamma_{c i}-$ usage coefficient of containers capacity in j-group; $n$-quantity of vehicles types; $m$ - quantity of containers types; $Q$ - annual total volume of SDW removing; $N_{n}$ - quantity of container points, un.; $n_{c j}^{a v}$ - average number of containers of $j$-type; $\beta$ - coefficient of mileage usage; $l_{t l i}$ - length of the trip with the load of $i$-group vehicles; $V_{t}$-technical speed of the vehicle, $\mathrm{km} / \mathrm{h} ; D_{w y}$ - days of work in a year; $T_{w}$ - time at work, h; $t_{i d j}$ - idle time while loading containers of $j$-type; $Q_{1,2}$ - respectively annual volumes of SDW removing when using vehicles of group1 and $2, \mathrm{~m}^{3} ; C_{1,2}$ - respectively cost of the vehicles of group 1 and 2, rub.; $[C]$ - maximum permissible cost of actions for the fleet improvement, rub.; $N_{i}^{\prime}$ - the corrected quantity of vehicles in i-group, un.; $C_{j}^{\prime}-$ the corrected quantity of containers in j-group, un.; $\Delta C, \Delta N$ - respectively change of vehicles cost and quantity, rub. 
3. The number of the vehicles and containers group which is most influencing the reduction of cost value of $1 \mathrm{~m}^{3}$ of SDW collecting and removing is established.

4. The actions cost for the structure perfection is determined and compared to the model restrictions on cost.

5 The vehicles and containers fleet is corrected, the efficiency evaluation of the implemented actions is carried out in case of the satisfaction to restrictions.

The program "The calculation of the quantity and the type of the vehicles for the specialized motor transport enterprise" is developed for the practical implementation of the given algorithm $[15,16]$.

\section{Results and Discussion}

The forming methodology of the research experimental base is proved. It includes the structure of the vehicles and container fleet for SDW collecting and removing, costs for their operation with the distribution on quarters, consisting in the reduction of operating costs to the base period.

The choice of the analysis methods, the interpretation and handling of the obtained data, the reliability reasons of the made research hypothesis is justified. The analysis and the interpretation of the experimental research results are performed by the method of the regression analysis using the program complex "Statistica".

The program "The calculation of the quantity and the type of the vehicles for the specialized motor transport enterprise" [12] was developed for the implementation of the forming algorithm for the rational structure of the vehicles and container fleet. This program considers the importance of these or other groups of the vehicles and the containers established as a result of the regression analysis and also the set restrictions for the model.

\section{References}

1. Ye.V. Bondarenko, A.O. Zuyev, I.I. Lyubimov, K.I. Manayev, A.N. Mel'nikov, Infrastructure optimization of collection and removal of solid domestic wastes from the settlement territory, in: Vestnik of the Moscow automobile and road construction state technical university (MADI), Moscow, № 4. pp. 92a-96 (2011)

2. J. Bie, H. K. Lo, Stability and attraction domains of traffic equilibria in a day-to-day dynamical system formulation. Transportation Research Part B 44 (1), 90-107 (2010)

3. I.I. Lubimov, K.I. Manayev, A.N. Melnikov, Calculation of the quantity and the type of the vehicles for the specialized motor transport enterprise [Electronic resource] : certificate on the state registration of the computer program; owner - Orenburg state university. - № 2016616975 from 01.07.2016 it is registered in the register of the computer programs 30.08.2016. - 1 p. (2016)

4. X. He, X. Guo, H. Liu, A link-based day to day traffic assignment model. Transportation Research Part B, 44 (4), 597 - 608 (2010)

5. B.G. Heydecker, Objectives, stimulus and feedback in signal control of road traffic. ITS Journal 8 (2), 63-76 (2004)

6. T-Y. Hu, H.S. Mahmassani, Day to day evolution of network flows under real-time information and reactive signal control. Transportation Research C, 5 (1), 51 - 69. (1997)

7. I.I. Lubimov, K.I. Manayev, A.N. Melnikov, Improvement results of the solid domestic waste collecting and removing process from the settlement territory. Progressive technologies in transport systems: materials collection of X International scientific and 
practical conference (April 24-26, 2013). Kumertau: Kumertau town printing house. Pp. 345-350 (2013)

8. I.I. Lubimov, K.I. Manayev, A.N. Melnikov, V.I. Rassokha, The algorithm development for the optimization of the rolling stock and container park at collecting and removing solid domestic wastes. Proceedings of the Tula state university. Technical sciences., Tula. № 4. pp. 174-182 (2011)

9. I.I. Lubimov, K.I. Manayev, A.N. Melnikov, N.Z. Sultanov, Methodical fundamentals of the process optimization for collecting and removing solid domestic wastes. Intellect. Innovations. Investments, Orenburg. № 2. Pp. 35-40 (2011)

10. I.I. Lyubimov, N.Z. Sultanov, Theoretical bases of perfection transport system. Bulletin of the Orenburg State University, 10, Pp. 121-123. (2014)

11. I.I. Lubimov, K.I. Manayev, A.N. Melnikov, N.Z. Sultanov, Specific function formation for the transport and logistic scheme optimization at collecting and removing of solid domestic wastes. Intellect. Innovations. Investments, Orenburg, № 3. pp. 5-8 (2011)

12. I.I. Lyubimov, A.N. Melnikov, N.A. Trubin The Control System Improvement of the City Motor Transportation Science Direct: Procedia Engineering. Volume 150. Pp. 1192-1199 (2016)

13. A.N. Melnikov, I.I. Lyubimov, K.I. Manayev Improvement of the Vehicles Fleet Structure of a Specialized Motor Transport Enterprise. Science Direct: Procedia Engineering. Volume 150. Pp. 1200-1208 (2016)

14. N.V. Vagapova, B.A. Portnikov, N.Z. Sultanov, I.I. Lyubimov. Functional processes management of city passenger transportation. Innovations. Investments., Orenburg, № 2, Pp. 49-56 (2009)

15. P. Varaiya, Max pressure control of a network of signalised intersections. Transportation Research Part C, Pp. 177-195. (2013)

16. J. G. Wardrop, Some theoretical aspects of road traffic research. Proceedings of the Institute of Civil Engineers Part II, 1, Pp. 325-378 (1952) 